\title{
Germinação das unidades de dispersão de gervão-roxo.
}

\author{
Claudia Antonia V. Rossetto'; Elson de C. Viegas²; João Nakagawa² \\ ${ }^{1 / U F R R J ~-~ I A, ~ D e p a r t a m e n t o ~ d e ~ F i t o t e c n i a, ~ 22.851-970 ~ S e r o p e ́ d i c a ~-~ R J ; ~}{ }^{2}$ UNESP - FCA, Departamento de Agricultura e Melhoramento \\ Vegetal, C. Postal 237, 18.603-970 Botucatu -SP. e-mail: cavrosse@ufrrj.br
}

\section{RESUMO}

Foram conduzidos dois experimentos com o objetivo de estudar a germinação das unidades de dispersão de gervão-roxo [Stachytarpheta cayennesis (L.C. Rich) Vahl], removidas de espigas que haviam sido armazenadas após terem sido colhidas em dois estádios de maturação. As unidades de dispersão foram removidas de espigas que se encontravam armazenadas por seis ou 18 meses e que haviam sido colhidas com a coloração verde ou palha. No primeiro experimento, as unidades de dispersão, incubadas no interior de caixas plásticas "tipo gerbox", foram distribuídas em folhas de papel germitest umedecidas com água destilada, sob temperatura de $20^{\circ} \mathrm{C}$ (noite) e $30^{\circ} \mathrm{C}$ (dia), na presença ou ausência de fotoperíodo de 12 horas, por 28 dias. No segundo experimento, as unidades de dispersão, incubadas no interior de caixas plásticas, foram distribuídas em folhas de papel germitest umedecidas com água destilada ou com solução de $\mathrm{KNO}_{3}$, sob temperatura de $20^{\circ} \mathrm{C}$ (noite) e $30^{\circ} \mathrm{C}$ (dia), na presença ou ausência de fotoperíodo de 12 horas, por 28 dias. A maior germinação foi obtida a partir de unidades de dispersão provenientes de espigas colhidas com a coloração palha e que se encontravam armazenadas por seis meses. A presença da luz, e o emprego de nitrato na ausência de luz, favoreceram a germinação das unidades de dispersão retiradas da parte apical e basal de espigas colhidas com a coloração verde ou palha e, armazenadas por seis ou 18 meses.

Palavras-chave: Stachytarpheta cayennesis; produção de sementes, qualidade fisiológica.

\begin{abstract}
Stachytarpheta cayennesis seeds germination.

Two experiments were carried out to study Stachytarphetas [Stachytarpheta cayennesis (L.C. Rich) Vahl] seeds (seedlike nutlets) germination. After harvesting, green and mature spikes were stored for 6-18 months. Seeds were removed from the spikes just after each storage period. In the first experiment, the seeds were incubated in plastic boxes with sheets of filter paper moistened with deionized water, set at $20^{\circ}$ (night) and $30^{\circ} \mathrm{C}$ (day), with or without a photoperiod of $12 \mathrm{~h}$, for 28 days. In the second experiment, those seeds were incubated in plastic boxes with sheets of filter paper moistened with deionized water or $\mathrm{KNO}_{3}$, set at $20^{\circ}$ (night) and $30^{\circ} \mathrm{C}$ (day), with or without a photoperiod of $12 \mathrm{~h}$, during 28 days. The best germination was observed in seeds from mature spikes stored for 6 months. Light and nitrate favored the germination of seeds from proximal and distal position in the spikes previously stored for 6 or 18 months.
\end{abstract}

Keywords: Stachytarpheta cayennesis, seed production, physiological quality.

\section{(Aceito para publicação em 04 de abril de 2.000)}

$\mathrm{P}$ ara as primeiras atividades organizadas na exploração e no estudo de plantas medicinais no Brasil, não havia a necessidade do cultivo, pois a simples coleta e o extrativismo de material vegetal, mais abundante na época, satisfaziam as necessidades da pesquisa, do uso e da comercialização. $\mathrm{O}$ crescente uso de plantas medicinais, por parte da indústria farmacêutica, estimulou o cultivo de hortas medicinais com a finalidade de atender a preservação da espécie, a seleção de variedades ou de clones mais adequados, a produção de material destinado ao estudos e à reprodução da planta (Ming, 1994). É o caso do gervão-roxo [Stachytarpheta cayennesis (L.C. Rich) Vahl], cujas sinonímias, são citadas por Kissmann \& Groth (1995) como sendo Verbena cayennensis L.C. Rich, Verbena jamaicensis (L.) Vahl, Verbena jamaicensis Vell., Stachytarpheta australis Mold.,
Stachytarpheta dichotoma (Ruiz \& Pav.) Vahl e Stachytarpheta polyura Schauer. Esta espécie é conhecida pelos seguintes nomes vulgares: gervãoazul (Kissmann \& Groth, 1995), gervãodas-taperas, rinchão, verbena-falsa (Pio Correa, 1926), gervão-do-campo (Castro \& Chemale, 1995), mocotó, richão, erva-gerbão, folha-de-verônica, ogervão, vassourinha-de-botão, urgebão, origão, oribão, verviene e chádo-Brasil (Almeida, 1993).

Esta planta é originária da América Tropical, com ocorrência na Austrália, no Havaí, na Índia (Dias Filho et al., 1995) e no Brasil, onde tem ampla distribuição, desde a Amazônia até o Rio Grande do Sul (Pio Correa, 1926; Castro \& Chemale, 1995), em particular na Amazônia Brasileira, em áreas consideradas mais secas (Dias Filho et al., 1995) e com uma cobertura de vegetação po- bre (Dias Filho, 1994b; Kissmann \& Groth, 1995). Tem sido considerada infestante de pastagens e de áreas de cultivo (Caribé \& Campos, 1991; Kissmann \& Groth, 1995).

O estudo farmacológico dessa espécie foi realizado por Costa (1960), quando determinou os seus princípios ativos (estarquitarina, citral, geraniol, verbecalina, dextrina e ácido ascórbico). Entre as virtudes da planta, tanto das folhas quanto das raízes, são a de combater as dores do peito e do estômago, bem como a de ser estimulante, febrífuga (Pio Corrêa, 1926), sudorífica e diurética (Almeida, 1993). Posteriormente, Caribé \& Campos (1991) e Viegas (1996) relataram que o decocto das folhas apresenta também propriedades inseticidas.

A propagação do gervão-roxo ocorre somente por reprodução sexuada, por 
meio de sementes produzidas, geralmente, aos pares dentro de frutos secos que desenvolvem-se em cavidades ao longo de espigas (Dias Filho, 1994b). Segundo Lopez-Palacios (1977), o gervão-roxo apresenta espigas longas com até $38 \mathrm{~cm}$ de comprimento e fruto capsular ovóide-lanceolado que se parte quando maduro em duas cocas, cada uma com uma semente (ereta, linear e sem endosperma). No entanto, para Castro \& Chemale (1995), os frutos de gervão-roxo são do tipo indeiscente, constituídos de esquizocarpos, cujas sementes são aderidas internamente ao fruto, contendo cada fruto uma só semente. Para Kissmann \& Groth (1995), a semente de gervão-roxo está inclusa no carcerulídio; o fruto desta espécie é denominado artrocarpáceo, apresenta-se com dois carcerulídios e está inserido em espigas lineares; os carcerulídios são denominados de unidades de dispersão.

Certos fatores físicos e químicos, aos quais as sementes dessa espécie estão naturalmente expostas no campo, afetam os padrões de sobrevivência e germinação, sugerindo que as práticas de cultivo que impedem as sementes de receberem luz, tal como o cultivo da terra, podem reduzir a ocorrência desta espécie temporariamente, pois quando estas são expostas à luz, elas germinam (Dias Filho, 1994a). Por outro lado, quando ocorre a roçagem, o número de ramos por planta é afetado negativamente, mas o número de espigas por ramo e o número de sementes por espiga e por ramo são favorecidos (Dias Filho et al., 1995).

Não foi observado nenhum efeito de nitrato na germinação de sementes de gervão-roxo, quando na presença de luz; no entanto, na ausência, foi verificado baixa germinação, o que sugere haver um mecanismo de estímulo do nitrato à germinação (Dias Filho, 1994a). Além disso, para sementes de Plantago lanceolata, Pons (1989) constatou quebra de dormência das sementes na presença de alta concentração de nitrato, quando o solo apresenta-se sem cobertura vegetal.

Em relação à longevidade das sementes de gervão-roxo, Dias Filho (1994a) observou que ocorreu uma perda de viabilidade de $55 \%, 52 \%$ ou $24 \%$ quando na superfície, a $5 \mathrm{~cm}$ e a $10 \mathrm{~cm}$, respectivamente, indicando que esta espécie pode compor o banco de sementes do solo.

O objetivo deste trabalho foi o de avaliar a germinação das unidades de dispersão de gervão-roxo, colhidas de espigas em dois estádios de maturação após um período de armazenamento.

\section{MATERIAL E MÉTODOS}

O trabalho, conduzido no Laboratório de Sementes do Departamento de Fitotecnia do Instituto de Agronomia da Universidade Federal Rural do Rio de Janeiro, em julho de 1997, constituiuse de dois experimentos.

No primeiro experimento, foram utilizadas espigas (infrutescência) de gervão-roxo [Stachytarpheta cayennesis (L.C. Rich) Vahl] que foram colhidas, em 19 de janeiro de 1997, quando apresentavam-se com a coloração ainda verde ou palha e, que, posteriormente, foram armazenadas por seis meses, em condições de ambiente sem controle de temperatura e umidade relativa do ar.

$\mathrm{O}$ delineamento experimental empregado foi inteiramente casualizado, em esquema fatorial $8 \times 2$ (fatores $\mathrm{x}$ metodologias de condução do teste), com quatro repetições. Tanto as espigas verdes como as maduras foram divididas em suas duas porções, apical e basal e, dessas foram retirados os frutos inteiros (artrocarpáceo). Cada fruto foi ou não separado em suas duas metades, denominadas, segundo Kissmann \& Groth (1995), de unidades de dispersão (carcerulídios) e, a seguir, foram submetidos à duas metodologias de condução do teste de germinação.

Para o teste de germinação, quatro repetições de 50 frutos inteiros ou 50 metades dos frutos foram conduzidas em papel germitest, umedecido com água destilada na proporção de 2,5 vezes o peso do papel, e colocadas no interior de caixas plásticas transparentes. Essas foram mantidas em germinador sob temperatura alternada de 20 a $30^{\circ} \mathrm{C}$, com fotoperíodo de 12 horas. Outras quatro repetições foram conduzidas em outro germinador sob temperatura alternada de 20 a $30^{\circ} \mathrm{C}$, na ausência de luz.

As contagens foram realizadas aos 10 e 28 dias após a instalação do teste, sob as condições de presença ou ausência de luz, com base nas recomendações encontradas nas Regras para Análise de Sementes (Brasil, 1992), para algumas espécies da família Verbenaceae. Quando foram empregados os frutos, que são compostos por duas metades, foi considerada a presença de pelo menos uma plântula normal (com comprimento mínimo de 2,0 cm).

$\mathrm{O}$ vigor foi determinado na primeira contagem do teste de germinação, pela avaliação das porcentagens de plântulas normais. Além disso, em cada tratamento determinou-se o grau de umidade dos frutos utilizando-se quatro repetições de 50 frutos, com base nas Regras para Análise de Sementes (Brasil, 1992).

No segundo experimento, foram utilizadas espigas de gervão-roxo colhidas, em 01 de janeiro de 1996, quando apresentavam-se com a coloração palha, e que encontravam-se armazenadas por 18 meses em condições de ambiente e, espigas colhidas, em 19 de janeiro de 1997, quando apresentavam-se com a coloração verde ou palha, e que encontravam-se armazenadas por seis meses nas mesmas condições de ambiente, sem controle de temperatura e umidade relativa do ar.

O delineamento experimental empregado foi o inteiramente casualizado, em esquema fatorial $6 \times 3$ (fatores $\mathrm{x}$ metodologias de condução do teste), com quatro repetições. Tanto das espigas verdes e armazenadas por seis meses, como das de coloração palha, que encontravam-se armazenadas por seis ou 18 meses, foram retirados os frutos inteiros (artrocarpáceos), sendo que esses foram ou não separados em suas duas metades, unidades de dispersão e em seguida foram submetidas a três condições do teste de germinação.

Para o teste de germinação, quatro repetições de 50 frutos ou 50 metades dos frutos foram colocadas em papel germitest, umedecido com água destilada na proporção de 2,5 vezes o peso do papel e, depositadas no interior de caixas plásticas. Estas foram mantidas em germinador sob temperaturas alternadas de 20 a $30^{\circ} \mathrm{C}$, com fotoperíodo de 8 horas. Outras quatro repetições foram conduzidas sob temperatura alternada de 
Tabela 1. Dados médios, em porcentagem, de grau de umidade, de germinação e de primeira contagem (vigor) das unidades de dispersão de gervão-roxo, coletados no Experimento I, em Seropédica. Rio de Janeiro, UFRRJ, 1997.

\begin{tabular}{|c|c|c|c|c|c|}
\hline \multicolumn{3}{|c|}{ Fatores } & \multirow{2}{*}{$\begin{array}{l}\text { Grau de } \\
\text { umidade }\end{array}$} & \multirow[b]{2}{*}{ Germinação } & \multirow[b]{2}{*}{$\begin{array}{l}\text { Primeira } \\
\text { Contagem }\end{array}$} \\
\hline Fruto & Parte da espiga & $\begin{array}{c}\text { Coloração da } \\
\text { espiga }\end{array}$ & & & \\
\hline Inteiro & Basal & Verde & 9,3 & $60,8 \mathrm{ab}$ & $28,8 \mathrm{a}$ \\
\hline Metade & Basal & Verde & & $59,0 \mathrm{ab}$ & $21,8 a b$ \\
\hline Inteiro & Apical & Verde & 9,5 & $48,0 \quad b$ & $4,0 \quad c$ \\
\hline Metade & Apical & Verde & & $47,8 \quad b$ & $8,5 \mathrm{bc}$ \\
\hline Inteiro & Basal & Palha & 9,1 & $65,0 \mathrm{a}$ & $36,0 \mathrm{a}$ \\
\hline Metade & Basal & Palha & & $63,2 \mathrm{a}$ & $27,2 \mathrm{a}$ \\
\hline Inteiro & Apical & Palha & 9,2 & $57,2 a b$ & $18,8 a b$ \\
\hline Metade & Apical & Palha & & $54,0 \mathrm{ab}$ & $20,2 \mathrm{ab}$ \\
\hline Com Luz & & & & $58,9 \mathrm{~A}$ & $23,6 \mathrm{~A}$ \\
\hline Sem Luz & & & & $56,1 \mathrm{~A}$ & $17,7 \mathrm{~B}$ \\
\hline C.V.(\%) & & & & 14,67 & 22,09 \\
\hline
\end{tabular}

* Médias seguidas da mesma letra maiúscula (para metodologia do teste) e minúscula (para unidades de dispersão) não diferem entre si, pelo Teste de Tukey, a $5 \%$ de probabilidade.

20 a $30^{\circ} \mathrm{C}$, na ausência de luz e, ainda outras quatro repetições foram testadas em papel umedecido com solução de $\mathrm{KNO}_{3}$, preparada de acordo com as Regras para Análise de Sementes (Brasil, 1992), e levadas para germinador sob temperatura alternada de 20 a $30^{\circ} \mathrm{C}$, na ausência de luz.

As contagens foram realizadas aos 10 e 28 dias após a instalação do teste, sob as três situações distintas, com base nas recomendações para a família Verbenaceae, encontradas nas Regras para Análise de Sementes (Brasil, 1992). Quando foram empregados os frutos, que são compostos por duas metades, foi considerada a presença de pelo menos uma plântula normal (com comprimento mínimo de 2,0 cm).

$\mathrm{O}$ vigor foi avaliado na primeira contagem do teste de germinação, considerando-se a porcentagem de plântulas normais nessa contagem. Além disso, determinou-se o grau de umidade dos frutos de cada tratamento utilizando-se, quatro repetições de 50 frutos com base nas Regras para Análise de Sementes (Brasil, 1992).

Foi realizada a análise de variância dos dados obtidos nos dois experimentos separadamente, sendo que os dados em porcentagem foram transformados previamente em arco seno $(\mathrm{x} / 100)^{1 / 2}$. As médias foram comparadas pelo teste de
Tukey, a 5\% de probabilidade. Os dados de grau de umidade não foram analisados estatisticamente.

\section{RESULTADOS E DISCUSSÃO}

O grau de umidade dos frutos inteiros (cada um composto por dois carcerulídios) e das metades destes frutos (um carcerulídio), retirados das espigas que estavam armazenadas, apresentavam-se entre 9,1 e 9,5\% (Tabela 1).

A maior germinação foi obtida quando empregaram-se frutos inteiros ou metades desses retirados da parte basal das espigas colhidas com a coloração palha, portanto, possivelmente, estas unidades de dispersão encontravam-se mais desenvolvidas por ocasião da colheita, uma vez que a maturação na espiga ocorre da porção basal para a porção apical. No entanto, a germinação não diferiu da obtida dos frutos inteiros ou de metades destes retirados da parte apical das espigas colhidas com a mesma coloração ou, ainda, da parte basal de espigas colhidas com a coloração verde (Tabela 1).

Em relação à metodologia do teste de germinação, não houve efeito significativo da luz na germinação dos frutos inteiros e das metades destes, independente da parte e da coloração das espigas em que foram retirados. Toda- via pode-se verificar que a menor porcentagem de plântulas anormais foi constatada na presença de luz, quando foram empregados frutos inteiros ou metades destes retirados de espigas colhidas com a coloração palha. Assim, com a luz, provavelmente, houve superação dos problemas de dormência, que causaram demora na germinação, pois pode-se verificar que as anormalidades caracterizaram-se pelo menor desenvolvimento das plântulas (Tabela 2).

A porcentagem de plântulas normais na primeira contagem (considerada para avaliar o vigor) foi maior quando empregaram-se frutos inteiros ou metades destes retirados da parte basal das espigas colhidas com a coloração palha, embora esta porcentagem não tenha diferido da obtida de frutos ou de metades destes, retirados da parte apical das espigas colhidas com a mesma coloração ou, ainda, da parte basal das espigas colhidas com a coloração verde, à semelhança do observado para a germinação (Tabela 1).

Em relação à metodologia de condução do teste de germinação, a maior porcentagem de plântulas normais na primeira contagem foi constatada na presença de luz, a qual pode ter ocasionado a superação dos problemas de dormência dos frutos ou das metades destes (Tabela 1). Tal resultado concor- 
Tabela 2. Dados médios, em porcentagem, de plântulas anormais das unidades de dispersão de gervão-roxo, coletados no Experimento I, em Seropédica. Rio de Janeiro, UFRRJ, 1997.

\begin{tabular}{|c|c|c|c|c|c|}
\hline \multicolumn{3}{|c|}{ Fatores } & \multirow{2}{*}{$\begin{array}{l}\text { Grau de } \\
\text { umidade }\end{array}$} & \multicolumn{2}{|c|}{ Plântula Anormal } \\
\hline Fruto & Parte da Espiga & $\begin{array}{c}\text { Coloração da } \\
\text { espiga }\end{array}$ & & Com Luz & Sem Luz \\
\hline Inteiro & Basal & Verde & 9,3 & 15,5 Aab & $17,5 \mathrm{Aab}$ \\
\hline Metade & Basal & Verde & & $22,5 \mathrm{Aab}$ & $28,5 \mathrm{Aa}$ \\
\hline Inteiro & Apical & Verde & 9,5 & $27,0 \mathrm{Aa}$ & 15,5 Bab \\
\hline Metade & Apical & Verde & & $17,5 \mathrm{Aab}$ & $16,0 \mathrm{Aab}$ \\
\hline Inteiro & Basal & Palha & 9,1 & $3,0 \mathrm{Bc}$ & $19,5 \mathrm{Ab}$ \\
\hline Metade & Basal & Palha & & $5,0 \mathrm{Bbc}$ & $14,5 \mathrm{Ab}$ \\
\hline Inteiro & Apical & Palha & 9,2 & $2,5 \mathrm{Bc}$ & $16,0 \mathrm{Ab}$ \\
\hline Metade & Apical & Palha & & $7,5 \mathrm{Bbc}$ & $12,0 \mathrm{Ab}$ \\
\hline$\overline{\text { C.V.(\%) }}$ & & & & & \\
\hline
\end{tabular}

* Médias seguidas da mesma letra maiúscula (para metodologia do teste) e minúscula (para unidades de dispersão) não diferem entre si, pelo Teste de Tukey, a $5 \%$ de probabilidade.

Tabela 3. Dados médios, em porcentagem, de grau de umidade, de germinação, de plântulas anormais e de primeira contagem (vigor) das unidades de dispersão de gervão-roxo, coletados no Experimento II, em Seropédica. Rio de Janeiro, UFRRJ, 1997.

\begin{tabular}{|c|c|c|c|c|c|c|c|c|c|c|c|c|}
\hline \multicolumn{3}{|c|}{ Fatores } & \multirow{2}{*}{$\begin{array}{c}\text { Grau } \\
\text { de } \\
\text { umi- } \\
\text { dade }\end{array}$} & \multicolumn{3}{|c|}{ Germinação } & \multicolumn{3}{|c|}{ Plântula Anormal } & \multicolumn{3}{|c|}{ Primeira Contagem } \\
\hline Fruto & $\begin{array}{r}\text { Armaze- } \\
\text { namento } \\
\text { (meses) }\end{array}$ & $\begin{array}{l}\text { Coloração } \\
\text { da espiga }\end{array}$ & & $\begin{array}{c}\text { Com } \\
\text { Luz } \\
\text { (água) }\end{array}$ & $\begin{array}{c}\text { Sem Luz } \\
\text { (água) }\end{array}$ & $\begin{array}{c}\text { Sem } \\
\text { Luz } \\
\left(\mathrm{KNO}^{3}\right)\end{array}$ & $\begin{array}{c}\text { Com } \\
\text { Luz } \\
\text { (água) }\end{array}$ & $\begin{array}{c}\text { Sem Luz } \\
\text { (água) }\end{array}$ & $\begin{array}{c}\text { Sem } \\
\text { Luz } \\
\left(\mathrm{KNO}^{3}\right) \\
\end{array}$ & $\begin{array}{c}\text { Com Luz } \\
\text { (água) }\end{array}$ & $\begin{array}{c}\text { Sem } \\
\text { Luz } \\
\text { (água) }\end{array}$ & $\begin{array}{c}\text { Sem } \\
\text { Luz } \\
\left(\mathrm{KNO}^{3}\right) \\
\end{array}$ \\
\hline Inteiro & 6 & Palha & 9,5 & $82,0 \mathrm{Aa}$ & $65,0 \mathrm{Ba}$ & $73 \mathrm{Aa}$ & $1,0 \mathrm{Ca}$ & $17,0 \mathrm{Abc}$ & $12,0 \mathrm{Ba}$ & $44,0 \mathrm{Aa}$ & $6,0 \mathrm{Ca}$ & $15,0 \mathrm{Ba}$ \\
\hline Metade & 6 & Palha & & $62,0 \mathrm{Ac}$ & $55,0 \mathrm{Bb}$ & $67 \mathrm{Aa}$ & $1,0 \mathrm{Ba}$ & $23,0 \mathrm{Ab}$ & $22,0 \mathrm{Aa}$ & 30,0 Aab & $4,0 \mathrm{Ca}$ & $8,0 \mathrm{Ba}$ \\
\hline Inteiro & 6 & Verde & 9,4 & $75,0 \mathrm{Ab}$ & $54,0 \mathrm{Bb}$ & $76 \mathrm{Aa}$ & $2,0 \mathrm{Ba}$ & $13,0 \mathrm{Abc}$ & $13,0 \mathrm{Aa}$ & $44,0 \mathrm{Aa}$ & $10,0 \mathrm{Ba}$ & $12,0 \mathrm{Ba}$ \\
\hline Metade & 6 & Verde & & $75,0 \mathrm{Ab}$ & $48,0 \mathrm{Bbc}$ & $76 \mathrm{Aa}$ & $4,0 \mathrm{Ba}$ & $11,0 \mathrm{Ac}$ & $15,0 \mathrm{Aa}$ & $37,0 \mathrm{Aab}$ & $4,0 \mathrm{Ca}$ & $9,0 \mathrm{Ca}$ \\
\hline Inteiro & 18 & Palha & 9,0 & $60,0 \mathrm{Ac}$ & $36,0 \mathrm{Bcd}$ & $71 \mathrm{Aa}$ & $1,0 \mathrm{Ca}$ & $23,0 \mathrm{Ab}$ & $10,0 \mathrm{Ba}$ & $17,0 \mathrm{Ab}$ & $0,0 \mathrm{Ca}$ & $8,0 \mathrm{Ba}$ \\
\hline metade & 18 & Palha & & $40,0 \mathrm{Bd}$ & $29,0 \mathrm{Bd}$ & $52 \mathrm{Ab}$ & $4,0 \mathrm{Ba}$ & $51,0 \mathrm{Aa}$ & $33,0 \mathrm{Aa}$ & $17,0 \mathrm{Ab}$ & $0,0 \mathrm{Ca}$ & $8,0 \mathrm{Ba}$ \\
\hline C.V.(\%) & & & & 14,66 & & & 15,25 & & & 19,20 & & \\
\hline
\end{tabular}

* Médias seguidas da mesma letra maiúscula (para metodologia do teste) e minúscula (para unidades de dispersão) não diferem entre si, pelo Teste de Tukey, a $5 \%$ de probabilidade.

da com os obtidos por Dias Filho (1994a), onde o cultivo da terra impede as sementes de receberem luz e pode reduzir a ocorrência desta espécie temporariamente, pois quando estas sementes são expostas à luz, elas germinam.

No segundo experimento, o grau de umidade dos frutos e das metades destes, retirados das espigas que estavam armazenadas, apresentavam-se entre 9,0 e 9,5\% (Tabela 3).

Verificou-se pela Tabela 3, que houve aumento da porcentagem de germinação dos frutos inteiros ou das metades desses retirados de espigas colhidas com a coloração verde ou palha e, ainda, armazenadas por seis meses, quando o teste foi conduzido na presença de luz. Tal resultado concorda com os obtidos por Dias Filho (1994a), onde as sementes dessa espécie apresentam comportamento fotoblástico positivo, pois as mesmas germinam na presença de luz.

Quando foi empregado o $\mathrm{KNO}_{3}$, na ausência de luz, também ocorreu o mesmo, mas, provavelmente, pela ação do nitrato que segundo Bewley \& Black (1992), o nitrato pode superar a dormência de muitas espécies, sozinho ou em combinação com alternância de temperatura e, ou, luz. Mas, no caso de gervão-roxo, Dias Filho (1994a) não observou efeito do nitrato na germinação das sementes, na presença de luz, após 14 dias da instalação; no entanto, na ausência de luz, foi verificada alguma germinação, sugerindo haver um mecanismo de estímulo deste à germinação. Resultado semelhante ocorreu para sementes de Plantago lanceolata, que germinaram na presença do nitrato e ausência de luz (Willians, 1983).

Com o armazenamento das espigas por 18 meses, observou-se que houve redução mais acentuada da germinação dos frutos ou das metades desses, principalmente, na ausência de luz. Além disso, constatou-se que houve diminuição da germinação das metades dos frutos retirados de espigas colhidas com a coloração palha, provavelmente, em função destas terem sido submetidas a dano mecânico ocorrido por ocasião da 
separação dos frutos, momentos antes da instalação do teste de germinação (Tabela 3).

As menores porcentagens de plântulas anormais foram observadas quando avaliaram-se as unidades de dispersão na presença de luz ou ainda quando foi empregada a solução de $\mathrm{KNO}_{3}$, durante a condução do teste de germinação. Cabe salientar que estas plântulas classificadas como anormais, ocasionadas provavelmente pelo atraso de sua germinação, causada por problema de dormência, na presença de luz ou de $\mathrm{KNO}_{3}$, puderam ser superadas, resultando em maior percentual de plântulas normais.

As maiores porcentagens de plântulas normais na primeira contagem foram observadas quando avaliaram-se as unidades de dispersão na presença de luz ou após o emprego de $\mathrm{KNO}_{3}$, na ausência de luz (Tabela 3). Assim, a primeira contagem neste caso pode representar uma manifestação de superação de dormência, e por isso, as unidades de dispersão germinaram mais rapidamente.

Em concordância com os resultados obtidos, a maior germinação foi obtida a partir de unidades de dispersão provenientes de espigas colhidas com a coloração palha e armazenadas por seis meses; a presença da luz e o emprego de nitrato, na ausência de luz, favoreceram a germinação das unidades de dispersão retiradas da parte apical e basal de espigas colhidas com a coloração verde ou palha e, armazenadas por seis ou 18 meses.

\section{AGRADECIMENTOS}

A Prof ${ }^{a}$ Dr $^{\mathrm{a}}$ Margarida Goréte Ferreira do Carmo, do Departamento de Fitotecnia da UFRRJ, pelas sugestões apresentadas.

\section{LITERATURA CITADA}

ALMEIDA, E.R. Plantas medicinais brasileiras: conhecimentos populares e científicos. São Paulo: Ed. Hemus, 1993, 341 p.

BEWLEY, J.D.; BLACK, M. Physiology and Biochemistry of seeds. Berlin: Springer Verlag, 1992. 375 p.

BRASIL. Ministério da Agricultura. Regras para análise de sementes. Brasília: SNDA/DNDV/ CLAV, 1992. 365 p.

CARIBÉ, J.; CAMPOS, J.M. Plantas que ajudam o homem. São Paulo: Pensamento, 1991. 321 p.

CASTRO, L.O.; CHEMALE, V.M. Plantas medicinais condimentares e aromáticas: descrição e cultivo. Guaíba: Agropecuária, 1995. 196 $\mathrm{p}$.

COSTA, O.A. Estudo farmacognóstico do gervão. Revista Brasileira de Farmácia, Rio de Janeiro, v. 41, n. 11/12, p. 615-650. 1960.
DIAS FILHO, M.B. Ecophysiological studdies of four Amazonian weedy species: implications for their invasive potential. Ithaca: Cornell University, 1994a. 220 p. (Tese doutorado).

DIAS FILHO, M.B. How is fecundity affected by mowing in the tropical weed Stachytarpheta Cayennensis (Verbenaceae). Pesquisa Agropecuária Brasileira, Brasília, v. 29, n. 11, p. 1675-1679, 1994b.

DIAS FILHO, M.B.; WISE, J.A.; DAWSON, T.E. Irradiance and water deficit effects on gas exchange behavior of two $\mathrm{C}_{3}$ amazonian weeds. Pesquisa Agropecuária Brasileira, Brasília, v. 30, n. 3, p. 319-325, 1995.

KISSMANN, K.G.; GROTH, D. Plantas infestantes e nocivas. São Paulo: BASF S.A.,T.3, 1995, 683 p.

LOPEZ-PALACIOS. S. Verbenaceae. Flora da Venezuela. Mérida - Venezuela: Talleres Gráficos Universitários, 1977. 654 p.

MING, L.C. Estudo e pesquisa de plantas medicinais na Agronomia. Horticultura Brasileira, Brasília, v. 12, n. 1, p. 3-10.1994.

PIO CORREA, M. Dicionário das plantas úteis do Brasil. v. III. Rio de Janeiro: Impressa Nacional, 1926. 646 p.

PONS, T.L. Breaking of seed dormancy by nitrate as a gap detection mechanism. Annals of Botany, v. 63, p. 139-143, 1989.

VIEGAS, E.C. Plantas medicinais em hortas caseiras: cultivo e usos. Seropédica: UFRRJ, 1996. 23 p.

WILLIAMS, E.D. Effects of temperature, light, nitrate and prechilling on seed germination of grassland plants. Annals of Applied Biology, v. 103, p. 161-172. 1983. 